\title{
Low-risk ankle injuries in children
}

\author{
Maxim Ben-Yakov MDCM, Kathy Boutis MD MSc
}

Cite as: CMAJ 2018 March 26;190:E367. doi: 10.1503/cmaj.170965

\section{Low-risk ankle injuries are the most common lower- extremity injuries in children}

Low-risk injuries in the lower extremities among children include lateral ankle sprains and isolated nondisplaced distal fibular SalterHarris I, II or avulsion fractures (Appendix 1, available at www.cmaj. ca/lookup/suppl/doi:10.1503/cmaj.170965/-/DC1). These injuries have excellent functional outcomes and are low risk for future complications. ${ }^{1}$

\section{The Low Risk Ankle Rule is a clinical decision rule that helps to reduce the use of unnecessary radiographs in children}

The rule (Figure 1), which is unique from the Ottawa Ankle Rules, identifies which ankle injuries in children are low risk. It was validated in children 3 to 16 years of age in six Canadian emergency departments. In a prospective multicentre implementation study that included 2151 children, this rule had $100 \%$ sensitivity and safely reduced imaging by $22 \% .{ }^{1}$ This rule is also cost-effective. ${ }^{2}$ Before applying the rule, physicians should do a comprehensive ankle examination, including the anterior joint line, and above and below the joint, to avoid missing distal fractures of the tibia (Appendix 2, available at www.cmaj.ca/ lookup/suppl/doi:10.1503/cmaj.170965/-/DC1). ${ }^{3}$

\section{3}

\section{Injuries suspected to be distal fractures of the fibular}

Salter-Harris I growth plate are almost always ankle sprain injuries

Because of presumed weakness of the growth plate relative to adjacent ligaments, children (who have immature skeletons) with isolated swelling and tenderness over the distal fibula and no radiographic evidence of fracture, are often diagnosed with Salter-Harris I fractures. However, a study that included 135 children who had this presentation showed that $97 \%$ actually had ligamentous injuries rather than growth plate fractures. ${ }^{4}$

\section{4}

Low-risk ankle fractures in children can be managed with symptomatic and supportive care

Randomized controlled trials have shown that management of these fractures with an ankle brace and a self-regulated return to activities was superior to a fibreglass cast or backslab for three weeks with respect to recovery. ${ }^{5}$

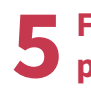

Follow-up of low-risk ankle fractures with a primary care physician is appropriate

Follow-up with an orthopedic surgeon is not necessary routinely and should be reserved for cases that are not improving as expected. ${ }^{4,5}$

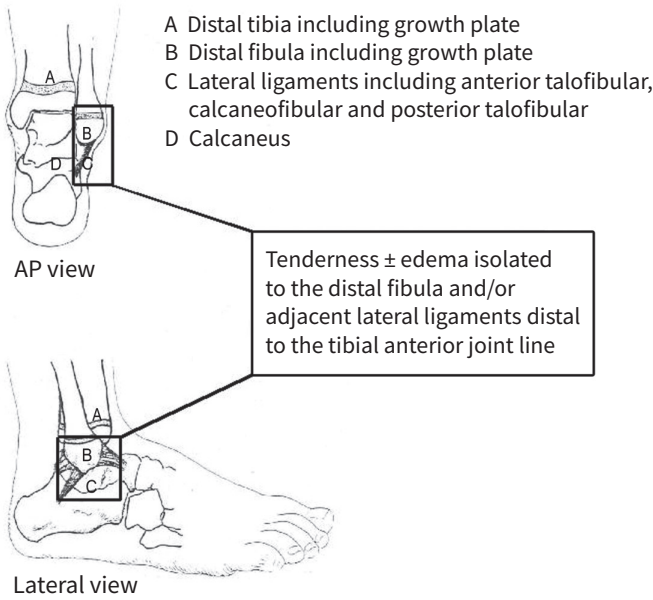

Figure 1: Low Risk Ankle Rule. If a child presents with a low-risk injury on examination (i.e., tenderness and swelling isolated to the distal fibula or adjacent lateral ligaments distal to the tibial anterior joint line), then radiography may not be necessary to exclude a clinically important ankle injury. Reproduced, with permission, from Boutis et al. ${ }^{6}$

\section{References}

1. Boutis K, Grootendorst P, Willan A, et al. Effect of the Low Risk Ankle Rule on the frequency of radiography in children with ankle injuries. CMAJ 2013;185:E731-8.

2. Ramasubbu B, McNamara R, Okafor I, et al. Evaluation of safety and cost-effectiveness of the Low Risk Ankle Rule in one of Europe's busiest pediatric emergency departments. Pediatr Emerg Care 2015;31:685-7.

3. Gravel J, Hedrei P, Grimard G, et al. Prospective validation and head-to-head comparison of 3 ankle Rules in a pediatric population. Ann Emerg Med 2009;54:534-40.e1.

4. Boutis K, Plint A, Stimec J, et al. Radiograph-negative lateral ankle injuries in children: occult growth plate fracture or ankle sprain? JAMA Pediatr 2016;170:e154114.

5. Barnett PL, Lee MH, Oh L, et al. Functional outcome after air-stirrup ankle brace or fiberglass backslab for pediatric low-risk ankle fractures: a randomized observer-blinded controlled trial. Pediatr Emerg Care 2012;28:745-9.

6. Boutis K, Komar L, Jaramillo D, et al. Sensitivity of a clinical examination to predict need for radiography in children with ankle injuries: a prospective study. Lancet 2001;358:2118-21.

Competing interests: None declared.

This article has been peer reviewed.

Affiliation: Division of Emergency Medicine, Hospital for Sick Children, University of Toronto, Toronto, Ont.

Correspondence to: Maxim Ben-Yakov, maxim.benyakov@utoronto.ca 